\title{
Interaction between topographic conditions and entrainment rate in numerical simulations of debris flow
}

\author{
Norifumi HOTTA ${ }^{*}$, Haruka TSUNETAKA ${ }^{1}$, Takuro SUZUKI² \\ 1 Faculty of Life and Environmental Sciences, University of Tsukuba, 3058577 \\ Ibaraki, J apan \\ 2 Forestry and Forest Products Research Institute, 3058687 Ibaraki, J apan \\ *Corresponding Author, e-mail: hotta.norifumi.ge@u.tsukuba.ac.jp
}

\begin{abstract}
Debris flow simulations is useful for upstream areas when predicting sediment supply to watersheds, that has been given as boundary conditions in many debris flow simulations. However, the topographic conditions in upstream areas are more complicated than those downstream, and the relationship between the topographic conditions and debris flow initiation is not well understood. This study compared several entrainment rate equations in numerical simulations of debris flows aiming to examine how topographic conditions can affect the flows. One-dimensional numerical simulations were performed based on the shallow water equations, and three entrainment rate equations were tested. These entrainment rate equations were derived based on the same idea that erosion and deposition of debris flows are occurred by the difference between the equilibrium and current conditions of debris flows, while were different in the styles expressed by the concentration, channel angle, and sediment amount, respectively. The comparison was performed using a straight channel with various channel angles and a channel with a periodically undulating surface. The results using the three entrainment rate equations showed different channel bed degradation and hydrographs on a straight channel with a channel angle greater than $21^{-}$, when steady water was given from upstream. The difference was caused by the expression of the entrainment rate equations. On channels with little undulation, the numerical simulations showed almost identical results compared to straight channels with the same channel angle. However, on channels with large undulations, the hydrographs differed from those on straight channels with the same channel angle when the channel angle was less than $21^{\circ}$. The quick erosion occurred and hydrograph showed significantly peaky shape, especially in case employing the entrainment equation expressed by channel angle. This was caused by the effects of the steep undulation sections since the effect increased with the undulation size suggesting that a debris flow in upstream area develop differently by the topographic conditions. These results also inferred that numerical simulations of debris flow can differ depending on the spatial resolution of the simulation domain, as the resolution determines the reproducibility of the undulations.
\end{abstract}

\section{Keywords:}

debris flow, entrainment rate equation, numerical simulation, topographic condition

\section{Introduction}


Numerical simulations of debris flow are used widely to develop hazard maps and to plan locations of arrays of check dams (e.g., Nakagawa and Takahashi 1997;Tsai 2007; Suzuki et al. 2011; Liu et al. 2012). In such numerical simulations, the governing equations for debris flow consist of the continuity equations and the momentum equation. The characteristics of debris flow are determined based on shear stress, expressed by the constitutive equations (Takahashi 1977; Tsubaki et al. 1982; Egashira et al. 1997; Miyamoto and Itoh 2002), and the sediment concentration. There have been several ideas as to dealing with the sediment concentration in debris flows.

Itoh and Miyamoto (2002), Hsu et al. (2010) and Wu et al. (2012) simply assumed that the sediment concentration in the debris flow was the equilibrium concentration (Takahashi, 1980) to be satisfied by the progress of river bed erosion or deposition; this assumption inherently leads to rapid erosion or deposition of the surface of the river bed. Although a few studies have tried to evaluate the entrainment rates theoretically (Iverson 2012), there is no consensus on the treatment of entrainment rate in debris flows (Hunger and Evans 2004). Hence, some models excluded the influence of entrainment in debris flows ( $\mathrm{O}^{\prime}$ Brien et al. 1993; Denlinger and Iverson 2001), and others introduced the entrainment rate empirically (Tai and Kuo 2008; Armanini et al. 2009; Peng et al. 2011). More specifically, entrainment rate equations have been proposed based on the concept of the equilibrium concentration and used to describe changes in sediment concentration in debris flows involved in river bed evolution (Takahashi and Kuang 1986; Egashira et al. 1988; Suzuki et al. 2009).

However, it has been pointed out that, even using the entrainment-rate equations, numerical simulations for debris flow do not reproduce river bed evolution well at points of abrupt change in the river form, such as constrictions and slope changes of the river bed, compared with experimental results (Takahama et al. 2002; Suzuki et al. 2009). Differences in river bed evolution between numerical simulations and flume tests can be seen by evaluating the topographic conditions in each entrainment rate equation (Tsunetaka et al. 2015). Thus, it is important to clarify the dependency of entrainment rate equations on topographic conditions, especially when predicting long-term sediment discharge by debris flows from upstream areas, where the topographic conditions in the upstream area are significantly complex.

In this study, we conducted numerical simulations for debris flow with three entrainment rate equations that are commonly used in Japan. The results were compared under various conditions to clarify how topographic conditions affect debris flow descent, focusing on the change in sediment concentration.

\section{$1 \quad$ Numerical simulation of debris flow}

\subsection{Governing equations}

A one-dimensional numerical simulation was carried out based on the following governing equations.

- continuity equation for debris flow:

$$
\frac{\partial h}{\partial t}+\frac{\partial M}{\partial x}=E
$$


- continuity equation for sediment:

$$
\frac{\partial(\bar{c} h)}{\partial t}+\frac{\partial\left(c_{t} M\right)}{\partial x}=E c_{*}
$$

- momentum equation for debris flow:

$$
\frac{\partial M}{\partial t}+\beta \frac{\partial(u M)}{\partial x}=-g h \frac{\partial H}{\partial x}-\frac{\tau_{0}}{\rho_{m}}
$$

where $\mathrm{h}$ is the flow depth, $\mathrm{M}$ is the discharge rate at the unit width, $\mathrm{E}$ is the entrainment rate at the bed, $\bar{C}$ is the mean sediment concentration in the cross section, $\mathrm{c}_{t}$ is the transport sediment concentration, $\mathrm{C} *$ is the sediment concentration in the channel deposition, $\beta$ is the momentum correction factor (Boussinesq's coefficient), $\mathrm{u}$ is the cross-sectional average velocity, $g$ is the acceleration due to gravity, $H$ is the elevation of flow surface $\left(H=h+z_{b}\right.$, where $\mathrm{z}_{\mathrm{b}}$ is the elevation of the bed), $\tau_{0}$ is the shear stress at the bed, and $\rho_{\mathrm{m}}$ is the density of debris flow.

The constitutive equations of Itoh and Miyamoto (2002) were employed, and $\tau_{0}$ was given as follows.

$$
\begin{aligned}
& \tau_{0}=\tau_{0 y}+\rho f_{b} u^{2} \\
& \tau_{0 y}=\left(\frac{\bar{c}}{c_{*}}\right)^{\frac{1}{5}}(\sigma-\rho) \bar{c} g h \cos \theta \tan \phi_{s} \\
& f_{b}=\frac{25}{4}\left\{K_{g}+K_{f}\right)\left(\frac{h}{d}\right)^{-2} \\
& K_{g}=k_{g} \frac{\sigma}{\rho}\left(1-e^{2}\right) \bar{c}^{\frac{1}{3}} \\
& K_{f}=k_{f} \frac{(1-\bar{c})^{\frac{5}{3}}}{\bar{c}^{\frac{2}{3}}}
\end{aligned}
$$

where $\rho$ is the density of water, $\sigma$ is the density of the sediment particles, $\theta$ is the bed slope angle, $\phi_{\mathrm{s}}$ is the internal friction angle of the sediment particles, $\mathrm{d}$ is the mean diameter of the sediment particles (a uniform particle size is given in this study), $\mathrm{k}_{\mathrm{g}}$ is a constant with a value of 0.0828 , e is the coefficient of the restitution of the sediment particles, and $\mathrm{k}_{\mathrm{f}}$ is the constant relating to interstitial space, with a value of 0.16.

\subsection{Entrainment rate equations}

The entrainment rate equation functions as a closure model in the governing equations for debris flow. There are four unknown parameters in Eqs. 1-3. An entrainment rate equation gives $\mathrm{E}$, one of the four unknown parameters. This study compares the three entrainment rate equations proposed by Takahashi and Kuang (1986), Egashira et al. (1988), and Suzuki et al. (2009). These equations have in common the assumptions that debris flow reaches an equilibrium state locally under given conditions, and accordingly that bed erosion and deposition occur according to the difference between the equilibrium and current state. 
However, the expressions of these relationships differ, as follows.

The entrainment rate equation by Egashira et al. (1988) is the simplest in expression and the clearest in concept. Egashira et al. (1988) used the concept of equilibrium bed slope $\theta_{\mathrm{e}}$, as expressed by Eq. 9, the value at which sediment flux between a debris flow and bed material is balanced, i.e., without erosion and deposition, under a given sediment concentration, and proposed the entrainment-rate equation given as Eq. 10. In Eq. 10, E is regarded as the change in $\theta$ toward $\theta_{\mathrm{e}}$ for a given sediment concentration when the bed surface is observed using a moving coordinate system with the debris flows velocity $u$. That is, bed erosion and sediment deposition occur when $\theta>\theta_{\mathrm{e}}$ and $\theta<\theta_{\mathrm{e}}$, respectively.

$$
\begin{aligned}
& \tan \theta_{e}=\frac{\bar{c}(\sigma / \rho-1)}{\bar{c}(\sigma / \rho-1)+1} \tan \phi_{s} \\
& E=u \tan \left(\theta-\theta_{e}\right)
\end{aligned}
$$

Takahashi and Kuang (1986) used equilibrium sediment concentration $\mathrm{C}_{\mathrm{e}}$, as expressed by Eq. 11, rewritten from Eq. 9, to evalutate the entrainment-rate Eqs 12 for erosion $\left(\mathrm{c}<\mathrm{C}_{\mathrm{e}}\right)$ and 13 for deposition $\left(\mathrm{c}>\mathrm{C}_{\mathrm{e}}\right)$.

$$
\begin{aligned}
& c_{e}=\frac{\rho \tan \theta}{(\sigma-\rho)\left(\tan \phi_{s}-\tan \theta\right)} \\
& E=\delta_{e} \frac{c_{e}-\bar{c}}{C_{*}-c_{e}} \frac{h}{d} u \\
& E=\delta_{d} \frac{c_{e}-\bar{c}}{C_{*}} u
\end{aligned}
$$

Here, $\delta_{\mathrm{e}}$ in Eq. 12 and $\delta_{\text {d }}$ in Eq. 13 are the coefficients for erosion and deposition, respectively. Takahashi and Kuang (1986) considered the balance of drive force and friction and argued that a debris flow induces erosion when the equilibrium point is below the current bed surface. Deposition was considered to occur when $\bar{c}>\mathrm{c}_{\mathrm{e}}$. The values for , $\delta_{\mathrm{e}}$ and $\delta_{\mathrm{d}}$ were given empirically (Nakagawa et al. 1996; Takahashi 2007), and the present study adopted 0.0007 and 0.1 (Nakagawa et al. 1996; Takahama et al. 2000), respectively. Based on this concept, several expressions for the entrainment-rate equation were proposed (Takahashi et al. 1988; Takahashi and Nakagawa 1991; Takahashi et al. 2000).

Suzuki et al. (2009) proposed the entrainment-rate equation, assuming that erosion and deposition occur depending on the difference in sediment amount in a debris flow between the equilibrium state and the current state, as shown in Eq. 14. In Eq. 14, $\mathrm{h}_{\mathrm{e}}$ is the flow depth of the equilibrium debris flow, which can be defined in same manner by deriving $\mathrm{C}_{\mathrm{e}}$ when $\theta$ and $\mathrm{M}$ are given, and $\mathrm{T}$ is a coefficient representing the time required to regulate the progress of erosion and deposition. We used the same value for $\mathrm{T}$ as Suzuki et al. (2009) did, with $1 / \mathrm{Tc}$ * corresponding to 3.0 .

$$
E=\frac{1}{T C_{*}}\left(h_{e} c_{e}-h \bar{c}\right)
$$




\section{Condition of simulation and analysis}

We carried out numerical simulations setting the flume at the initial condition as a straight channel having a flat bed surface with various channel angles and surfaces with small and large undulations with fixed angles. The length and width of the flume were set to $200 \mathrm{~m}$ and $1 \mathrm{~m}$, respectively, for each numerical simulation, as this study emphasized the sensitivity analysis. Debris flows can differ markedly in fluidity (Imaizumi et al. 2005) and erosion (Hunger and Evans 2004; McCoy et al. 2012) in the case of saturated versus unsaturated bed deposition. Hence, the initial channel bed was treated as saturated for simplicity, although in-situ bed deposition is regarded under various moisture conditions in the debris flow initiation area (Ikeda et al. 2011). For the boundary condition, the bed elevation of the lower end was fixed with that of the initial bed, so that not all of the bed deposition is eroded and the lower end determines the final shape of the deposition. The bed deposition depth and sediment particle size are from Imaizumi et al. (2006).

In accordance with the study aim, we tested three different flume conditions: flat, moderately, and markedly undulating beds. For the flat bed cases, the initial bed material depth was given as $15 \mathrm{~m}$, and the simulations were conducted on the flume at $15^{\circ}$, increasing to $30^{\circ}$ in $1^{\circ}$ increments. For the cases of undulating surfaces, the average slope angle was set at $20^{\circ}$, with periodic undulations consisting of isosceles triangles. The base angle of the triangles was $18^{\circ}$, and the base lengths were set at $4 \mathrm{~m}$ and $8 \mathrm{~m}$ for little and large undulation, respectively. The amount of initial bed material was set to correspond to one of the flat-bed cases.

The parameters used in the numerical simulations are shown in Table 1. Water was supplied from the upper end of the flume at $0.183 \mathrm{~m}^{3} / \mathrm{s}$ for $600 \mathrm{~s}$. Although small amounts of sediment were supplied as needed to achieve a debris-flow simulation, the main body of the debris flow was generated by erosion of the bed material. The upper limit of $\mathrm{c}_{\mathrm{e}}$ was set not to exceed c*. The leap-flog scheme was used in the calculations, with a temporal resolution of 0.01 $\mathrm{s}$ and spatial resolution of $1 \mathrm{~m}$ for the calculation step to satisfy the Courant-Friedrichs- Lewy condition for debris flow (Itoh and Miyamoto 2002). The computational time for each case was several seconds.

In comparing the results from the numerical simulations, we focused on the final channel bed at $600 \mathrm{~s}$ after the start of the simulation, a debris-flow hydrograph at the lower end, and the time series of sediment concentration. First, the responses of the entrainment rate equations to bed slope angle were compared based on the results of the flat-bed cases. Then, referring to the results from the cases of undulating surfaces, we examined how topographic conditions affected the debris flow descent.

\section{Results}

\subsection{Debris flow in a flat-bed channel}

The calculated results of channel bed evolution differed by the inclination of the bed angle, and the differences among the erosion rate equations also varied by bed angle. Figure 1a illustrates the channel bed evolution in a $20^{\circ}$ flume. The results of the cases using the entrainment rate equations of Egashira et al. (1988) and Suzuki et al. (2009) corresponded well, whereas the results using Takahashi and Kuang (1986)'s equation showed less erosion in 
the upper section, resulting in linear degradation for the whole domain. The smallest amount of eroded sediment was found with Suzuki et al. (2009) in the $25^{\circ}$ channel (Figure 1b). The amount of eroded sediment increased with increasing bed angle.

Figure 2 shows the relationship between initial channel bed angle and the total amount of sediment eroded after $600 \mathrm{~s}$ for each entrainment equation. The eroded sediment, calculated with the three entrainment rate equations showed rapid increase after the bed angle exceeded $20^{\circ}$ in common. On the other hand, the magnitude of the relationship among the equations changed after $20^{\circ}$.

The hydrograph also differed according to the entrainment rate equations. Figure 3 shows the hydrograph obtained at the lower end of the channel at $20^{\circ}$ and $25^{\circ}$. In the $20^{\circ}$ channel (Figure 3a), the entrainment rate equations of Egashira et al. (1988) and Suzuki et al. (2009) provided identical peak discharge and time of appearance, whereas the decrease after the peak was gentler with Egashira et al. (1988). The results of Takahashi and Kuang (1986)'s equation showed delayed discharge, with a lower peak and gentler decrease compared with Egashira et al. (1988) and Suzuki et al. (2009). The shape of the hydrograph depended on the bed angle in a manner similar to the results for channel bed evolution. Figure $3 \mathrm{~b}$ illustrates the results for the $25^{\circ}$ channel. The erosion progressed rapidly using the equation of Egashira et al. (1988), flushing most of the bed material within $90 \mathrm{~s}$, resulting in a spike in the peak discharge as validated by Osti and Egashira (2009). The Takahashi and Kuang (1986)'s equation resulted in the second largest peak discharge, with a moderate decrease. With both Egashira et al. (1988) and Takahashi and Kuang (1986), the discharge tended toward correspondence with the water discharge supplied from the upper end, indicating that all of the bed material had been eroded, whereas Suzuki et al. (2009) still showed very moderate decrease at the end of the calculation, following the lowest peak discharge among the three entrainment rate equations.

Figure 4 compares the time series of sediment concentration at the upper end, middle, and lower end of the channel. In the channel of $20^{\circ}$ bed slope (Figure 4a-c), all the entrainment rate equations finally gave results with similar values of sediment concentration at the lower end although the profiles showed slight differences. However, at the upper end of the channel, the sediment concentration according to Takahashi and Kuang (1986) showed a consistently low value, $\sim 0.15$, whereas the sediment concentrations according to Egashira et al. (1988) and Suzuki et al. (2009) increased, up to 0.4 at the initial stage, and then decreased gradually. In the $25^{\circ}$ channel (Figure $4 \mathrm{~d}-\mathrm{f}$ ), sediment concentrations according to any of the entrainment rate equations increased rapidly in all sections. However, the pattern of decrease varied by the equations and location.

\subsection{Debris flow on an undulating bed surface}

As shown in Section 3.1, the erosion rate of debris flow differed by the slope of the channel with a flat bed, and the erosion rate increased with increasing bed slope. In the case of an undulating bed surface, the erosion rate also increased rapidly when the average slope angle was substantially high, resulting in no significant difference from the results of the flat-bed channel; however, the results differ by the size of the undulation when the average slope angle is relatively small.

Figure 5 shows the channel bed evolution with a $20^{\circ}$ flume and an undulating bed 
surface. Compared with Figure 1, the final channel bed shape did not differ from that of the flat-bed channel regardless of the undulation size. However, the hydrograph was changed by the undulation as shown in Figure 6. A comparison with Figure 3 reveals that, whereas the difference was negligible when the undulation was small (Figure 6a), the peak discharge increased with any entrainment rate equations in the case of larger undulations (Figure 6b). The peak discharge increased by about three fold using Takahashi and Kuang (1986), by a factor of two using Egashira et al. (1988), and by about one-half using Suzuki et al. (2009). The final discharge rate was comparable to that of the flat-bed channel, although the decrease from peak discharge was significantly steeper using Takahashi and Kuang (1986).

Figure 7 compares the time series of sediment concentration for channels with undulating bed surface. Compared with Fig. 4a-c, the equation proposed by Egashira et al. (1988) (Figure 7a, 7d) and Suzuki et al. (2009) (Figure 7c, 7f) show almost identical results, whereas that by Takahashi and Kuang (1986) (Fig. 7b, 7e) showed a rapid increase in sediment concentration in the debris-flow front at any section of the channel.

\section{Discussions}

\subsection{Relationship between bed slope angle and upper limit of concentration equilibrium}

The results of the numerical simulations of debris flow in a flat-bed channel (Figure 1-4) did not reveal significant differences in the hydrograph or the amounts of channel bed erosion according to the three entrainment rate equations when the bed slope was less than $20^{\circ}$, although Takahashi and Kuang (1986) showed relatively small values. However, when the bed slope angle exceeded $20^{\circ}$, the erosion rate increased rapidly (Figure 2), resulting in differences in the final shape of the channel bed (Figure 1b) and the hydrograph (Figure 3b). This differentiation by bed slope angles is considered to be induced by debris-flow concentration, which is strongly affected by bed slope angle on an erodible bed. When physical parameters (Table 1) are substituted in Eq. 11 to derive the relationship between bed slope angle $\theta$ and debris-flow concentration, the equilibrium concentration, $\mathrm{C}_{\mathrm{e}}$, is satisfied, with $\mathrm{c}_{\mathrm{e}} \leq \mathrm{c} *$ when $\theta<\sim 21$. Here, $\mathrm{c} *$ should be the upper limit of the sediment concentration, and we set the critical bed slope angle as $\theta_{c}$ when $\mathrm{c}_{\mathrm{e}}=\mathrm{c} *$ in Eq. 11 .

Assuming a steady and uniform debris flow in an infinitely long channel in an equilibrium state, the external driving force and the frictional resistance are balanced on the surface of the erodible bed. However, when $\theta$ exceeds $\theta_{c}$, as the external driving force is always larger than the frictional resistance, all the bed material is rapidly eroded, resulting in the total bed deposition becoming fluidized. The results shown in Figure 2 are considered to reflect this condition; the existence of an upper limit of sediment-concentration equilibrium accelerated channel bed erosion markedly in the case of $\theta>\theta_{c}$. Furthermore, the differences among the entrainment rate equations were larger when $\theta>\theta_{c}$ (e.g., results for $25^{\circ}$ in Figure $1 \mathrm{~b}$ and $2 \mathrm{~b}$ ), as the response of each entrainment rate equation was possibly different when $\bar{c}$ exceeded $c$.

In a headwater area of a mountain torrent or huge landslide area in which the topographic conditions are not only steep but also complex, even when the average bed slope is less than $\theta_{c}$, the local relief can be $\theta>\theta_{c}$, as in the case of the initial bed surface in Figure 5. Here, all three entrainment rate equations assessed in this study assume that an equilibrium 
state can be realized locally, regardless of the average slope of the whole channel. That is, the entrainment rate is evaluated at a point, referring to the local equilibrium state, which is usually derived based on the local bed slope. According to the fundamental concept of the equilibrium state, all the bed deposition should be flushed instantly when $\theta>\theta_{c}$. However, it is not clear whether this concept can be applied to a channel in which local bed slope varies widely, exceeding $\theta_{\mathrm{c}}$ at times. Thus, at present, it would be difficult to verify the reproducibility of the entrainment rate equations under complex topographic conditions (Figure 5).

Considering the differing dependencies, it would be useful in practice to compare the response of each entrainment rate equation to topographic conditions in cases of $\theta>\theta_{\mathrm{c}}$ to assess the debris flow runout at the initial stage in the upper basin region. Additionally, the numerical simulations of debris flow often introduce some restraints for the entrainment rate equation to stabilize the calculation, especially when an unsteady feature is significant, such as numerical simulations of complex topographic conditions (Suzuki, 2013). To evaluate the appropriateness of the simulated results, an understanding of the fundamental features of the entrainment rate equations is essential.

\subsection{Response of entrainment-rate equation}

In this section, fundamental features of each of the entrainment rate equations used in this study are examined based on the simulated results in Section 4 , focusing on the dependency on topographic conditions, mainly when $\theta>\theta_{\mathrm{c}}$.

\subsubsection{Egashira et al. (1988)}

The amount of eroded sediment and the peak discharge were the highest with the entrainment rate equation of Egashira et al. (1988) in the flat-bed channel with $\theta>\theta_{c}$ (Figure $1 \mathrm{~b}, 3 \mathrm{~b})$. When $\theta>\theta_{\mathrm{c}}, \theta$ in Eq. 10 satisfies $\theta>\theta_{\mathrm{c}}$ at any time, and consequently, the entrainment rate equation always yields erosion. Because the entrainment rate is determined by $u$ and $\left(\theta-\theta_{\mathrm{e}}\right)$ with this equation, erosion occurs regardless of sediment concentration and depth of debris flow. Intense erosion leads to a rapid increase in debris-flow volume, resulting in an increase in momentum due to gravity acceleration and consequently an increase in velocity, resulting in significant channel bed evolution and peak discharge (Figure $1 \mathrm{~b}, 3 \mathrm{~b}$ ).

The response of debris flow to undulations of the bed surface can be explained based on the dependency of debris flow on bed slope, as described above. A single undulation is composed of steep and mild slopes. When $\theta$ exceeds $\theta_{c}$ at the steep section of the undulation, the undulation is quickly eroded from the steep section. Because the undulation tends to become flat after the steep section is eroded, the final channel bed corresponds to that of a flat bed (Figure 1a) regardless of the size, as shown in Figure 5a, b; that is, the total amount of eroded sediment is determined by average bed slope.

However, the peak discharge is changed significantly when the sizes of undulations differ, even when the average bed slope is less than $\theta_{c}$ (Figure 6a, b). The peak discharge was generated at the initial stage of debris flow. This can be interpreted as the eroded sediment, and the interstitial water in the steep section just after the water supply accumulated to form the peak discharge. The reason that the size of the undulation affects the result is considered to be that more momentum to develop the debris flow can be obtained in a longer section in 
which the slope is steep. This difference by undulation size was not detected when the average bed slope was greater than $\theta_{c}$, indicating that the debris-flow hydrograph in a channel with an undulated bed surface is determined by the average bed slope when $\theta>\theta_{\mathrm{c}}$.

\subsubsection{Takahashi and Kuang (1986)}

The amount of eroded sediment and the peak discharge according to Takahashi and Kuang (1986) were the second largest after Egashira et al. (1988) in the flat-bed channel with $\theta>\theta_{c}$ (Figure 1b, 3b). As shown in Eqs. 12 and 13, the erosion and deposition rates in the entrainment rate equation by Takahashi and Kuang (1986) are in proportion to $\left(\mathrm{C}_{e}-\mathrm{c}\right)$. This means that the increase in erosion rate is damped when ce reaches the upper limit of sediment concentration $\mathrm{C}$. Consequently, the erosion was not highly significant compared with Egashira et al. (1988). Also, the upper limit of $\mathrm{Ce}_{\mathrm{e}}$ could induce fluctuations in the hydrograph (Figure 3b) when the sediment concentration increased rapidly. Additionally, erosion $\left(\delta_{\mathrm{e}}\right)$ and deposition $\left(\delta_{\mathrm{d}}\right)$ coefficients in Eqs. 12 and 13, respectively, have been reported to result in less erosion and deposition rate compared with Eq. 10 (Takahama et al. 2000), as shown in Figure 4b, where a greater distance was required for sediment concentration to increase according to Takahashi and Kuang (1986).

Although the response to undulations in the bed surface was basically the same as that for Egashira et al. (1988), the hydrograph in the present case was more affected by the size of the undulation (Figure 6b). Fluctuations in the time series of sediment concentrations due to the undulation size (Figure $7 \mathrm{~b}, 7 \mathrm{e}$ ) are considered to induce variation in the hydrograph. However, if the undulation size is large enough so that the sediment concentration is increased to the upper limit, the influence of undulation size can be negligible. In fact, the peak discharge was less significant than that according to Egashira et al. (1988) in the flat-bed channel with $\theta>\theta_{\mathrm{c}}$ (Figure 3b).

\subsubsection{Suzuki et al. (2009)}

The amount of eroded sediment and the peak discharge obtained with the entrainment rate equation of Suzuki et al. (2009) were less than those with the other equations in the flat-bed channel with $\theta>\theta_{c}$ (Figure 1b, 3b). This entrainment-rate equation assumes that sediment erosion / deposition occurs, as shown in Eq. 14, in proportion to the difference between current sediment amount in the debris flow and the equilibrium sediment amount that is expressed as the product of the equilibrium flow depth $h_{e}$ and the equilibrium sediment concentration $\mathrm{c}_{\mathrm{e}}$. Here, $\mathrm{h}_{\mathrm{e}}$ is obtained from the current bed slope angle and debris flow discharge rate. Because the debris flow discharge itself is affected by erosion / deposition, the two interact. Thus, a debris flow in the early phase, when the discharge rate is still moderate, does not induce significant erosion. Moreover, debris-flow velocity is implicit in this equation, indicating that development of a debris flow may have different effects in this compared with the other two entrainment rate equations.

Accordingly, the response to topographic conditions could be more complex with the entrainment rate equation of Suzuki et al. (2009) than with the others. As shown in Figure 2, the relationship of bed slope angle versus channel bed erosion is a complex curve. As discussed in the previous sections, with the entrainment rate equations of Takahashi and Kuang (1986) 
and Egashira et al. (1988), the effect of undulations is determined mainly by the response of debris flows in the steep section. Suzuki et al. (2009)'s equation shows comparable results in a channel with an undulating bed surface (Figure 6b), although the results in a steep, flat-bed channel were the most modest (Figure 1b, 3b). The entrainment rate equation by Suzuki et al. (2009) can be regarded as intermediate in that the upper limit of sediment concentration regulates the erosion, as with Takahashi and Kuang (1986), and the erosion / deposition rate is not entirely limited, as with Egashira et al. (1988).

\subsection{Debris flow development is affected by topographic conditions}

As shown in the preceding sections, complex topographic conditions, such as intensive undulations of the bed surface, affected the hydrograph of debris flows in the numerical simulations. The variations were induced by the debris-flow responses in the steep sections, and these differed according to the entrainment rate equations. Although Zhou et al. (2015) demonstrated that bed erosion contributed to formation of the peak discharge of debris flow experimentally, the results of that study were not compared to in-situ debris flows. However, the findings are still important in the following respects.

When the average bed slope angle was less than $\theta_{c}$, and when the slope of steep sections was larger than $\theta_{c}$, undulations of the bed surface generated distinguishable peak discharges in the case of larger undulation sizes (Figure 6a, 6b). Quite similar results were obtained with all three entrainment rate equations despite the different expressions for each equation. That is, actual debris flows can be considered to behave in approximately the same manner in a channel with an undulating bed surface using any of the three equations, given the assumption (which is adopted by them all) that bed evolution by debris flow is driven by the difference between the equilibrium and current state of debris flow. That is, it is necessary to consider local topographic conditions when predicting debris flow development. The continuous length of the steep section of undulations was key factor controlling the peak discharge of debris flow, as discussed previously. The continuous length can vary depending on the resolution of topographic data or computational grid size in a numerical simulation, even for the same site. Consequently, a numerical simulation of debris flow may produce different results depending on the calculation conditions when the topography in a target torrent is complex.

Moreover, this insight should be important when conducting field investigation after a debris flow runout. In field investigations of debris flow, attention is often paid to evidence of the maximum flow height to estimate the magnitude and to reproduce the hydrograph of a debris flow. Our results indicate that not only rainfall patterns but also topographic conditions affect the hydrograph shape in a channel with surface undulations and sufficient sediment deposition. Under such conditions, debris flows cannot be treated simply as a "kinematic wave." Considering topographic conditions, the hydrograph can be estimated more accurately by back analysis based on the signature of the debris-flow height.

\section{Conclusions}

We compared three entrainment rate equations in numerical simulations of debris flows to examine how topographic conditions can affect such flows. The results using the three 
entrainment rate equations showed different channel bed degradation and hydrographs for a straight channel with a channel angle greater than the critical value at which equilibrium sediment concentration was equal to the maximum sediment concentration. In channels with little undulation, the numerical simulations showed almost identical results to the case of straight channels with the same channel angle. However, in channels with large undulations, the hydrographs differed from those of straight channels with the same channel angle when the average channel angle was less than the critical value. This was caused by the effects of the steep sections of the undulation, and this effect increased with undulation size, whereas the fundamental features of the flows were governed by the channel angle. These results also indicate that numerical simulations of debris flow can differ depending on the spatial resolution of the simulation domain and that considering the influence of topographic conditions is essential in evaluating in-situ debris flow development.

\section{Acknowledgments}

We sincerely thank Prof. Kuniaki Miyamoto (University of Tsukuba) and Prof. Shinji Egashira (International Center of Excellence for Water Hazard and Risk Management, J apan) for their insightful comments on this study. This research was partially supported by Grant-in-Aid for Scientific Research 26292077, 2014, from the Ministry of Education, Science, Sports, and Culture of J apan, and by the River Fund in charge of the River Foundation, J apan. 


\section{References}

Armanini A, Fraccarollo L, Rosatti G (2009) Two-dimensional simulation of debris flows in erodible channels. Computers \& Geosciences 35: 993-1006. doi: 10.1016/j.cageo.2007.11.008

Denlinger RP, Iverson RM (2001) Flow of variably fluidized granular masses across three-dimensional terrain: 2. Numerical prediction and experimental tests. Journal of Geophysical Research 106: 553- 566. doi: 10.1029/2000J B900330

Egashira S, Ashida K, Sasaki H (1988) Mechanics of debris flow in open channel. Proceedings of the Japanese Conference on Hydraulics, Japan Society of Civil Engineers, 32: 485- 490. (in J apanese with English summary)

Egashira S, Miyamoto K, Itoh T (1997) Constitutive equations of debris flow and their applicability. In: Proceedings of the 1st International Conference on Debris-Flow Hazards Mitigation, San Francisco, California, US, 7- 9 August 1997. pp 340-349.

Hsu SM, Chiou LB, Lin GF, Chao CH, Wen HY, Ku CY (2010) Applications of simulation technique on debris-flow hazard zone delineation: a case study in Hualien County, Taiwan. Natural Hazard and System Sciences 10: 535-545. doi: 10.5194/nhess-10-535-2010

Hunger O, Evans SG (2004) Entrainment of debris in rock avalanches: An analysis of a long run-out mechanism. Geological Society of America Bulletin 116: 1240-1252. doi: 10.1130/B25362.1

Itoh T, Miyamoto K (2002) Study on one dimensional numerical simulation of debris flow. Proceedings of hydraulic engineering, J SCE, 46: 671-676. (in Japanese with English summary)

Ikeda A, Mizuyama T, Sugiura N, Hasegawa Y (2011) Deformation of stream bed deposit and runoff process at debris flow initiation zone. In: Proceedings of the 5th International Conference on Debris-Flow Hazards Mitigation, Padua, Italy, 14-17 J une 2011. pp 91-99.

Imaizumi F, Tsuchiya S, Ohsaka O (2005) Behavior of debris flows located in a mountainous torrent on the Ohya landslide, J apan. Canadian Geotechnical J ournal, 42: 919- 931. doi: 10.1139/t05-019

Imaizumi F, Sidle RC, Tsuchiya S, Ohsaka O (2006) Hydrogeomorphic processes in a steep debris flow initiation zone. Geophysical Research Letters 33: L10404. doi: 10.1029/ 2006GL026250

Iverson RM (2012) Elementary theory of bed-sediment entrainment by debris flows and avalanches. J ournal of Geophysical Research 117: F03006. doi:10.1029/2011J F002189

Liu J, Nakatani K, Mizuyama T (2012) Hazard mitigation planning for debris flow based on numerical simulation using Kanako simulator. Journal of Mountain Science 9 (4): 529- 537. doi: 10.1007/ s11629-012-2225-9

McCoy SW, Kean JW, Coe JA, Tucker GE, Staley DM, Wasklewicz TA (2012) Sediment entrainment by debris flows: In situ measurements from the headwaters of a steep catchment. J ournal of Geophysical Research, 117: F03016. doi: 10.1029/ 2011J F002278

Miyamoto K, Itoh T (2002) Numerical simulation method of debris flow introducing the erosion rate equation. J ournal of the J apan Society of Erosion Control Engineering 55 
(2): 24- 35. (in J apanese with English summary)

Nakagawa H, Takahashi T, Sawada T, Satofuka Y (1996) Design hydrograph and evacuation planning for debris flow. Annals of the Disaster Prevention Research Institute, Kyoto University 39 (B-2): 347- 371. (in J apanese with English summary)

Nakagawa H, Takahashi $T$ (1997) Estimation of a debris flow hydrograph and hazard area. In: Proceedings of the 1st International Conference on Debris-Flow Hazards Mitigation, San Francisco, California, US, 7- 9 August 1997. pp 64- 73.

O'Brien JS, Julien PY, Fullerton T (1993) Two-dimensional water flood and mudflow simulation. J ournal of Hydraulic Engineering 119 (2): 244- 261.

Osti R, Egashira S (2009) Hydrodynamic characteristics of the Tam Pokhari glacial lake outburst flood in the Mt. Everest region, Nepal. Hydrological Processes 23: 2943- 2955. doi: 10.1002/ hyp.7405

Peng H, Zhao Y, Cui P, Zhang W, Chen X, Chen X (2011) Two-dimensional numerical model for debris flows in the Jiangjia gully, Yuunan province. J ournal of Mountain Science 8 (6): 757- 766. doi: 10.1007/ s11629-011-2043-5

Suzuki T (2013) Method for processing an erosion rate equation in numerical simulation of debris flow. J ournal of the J apan Society of Erosion Control Engineering 65 (5): 21- 28. (in J apanese with English summary)

Suzuki T, Hotta N, Miyamoto K (2009) Numerical simulation method of debris flow introducing the non-entrainment erosion rate equation, at the transition point of the riverbed gradient or the channel width and in the area of sabo dam. Journal of the J apan Society of Erosion Control Engineering 62 (3): 14- 22. (in J apanese with English summary)

Suzuki T, Hasegawa Y, Mizuno H, Osanai N (2011) Monitoring near-riverbed sediment behavior of debris flows using hydrophones. In: Proceedings of the 5th International Conference on Debris-Flow Hazards Mitigation, Padua, Italy, 14- 17 J une 2011. pp 615- 622.

Tai YC, Kuo CY (2008) A new model of granular flows over general topography with erosion and deposition. Acta Mechanica 199: 71-96. doi: 10.1007/ s00707-007-0560-7

Takahama J, Fujita Y, Kondo Y (2000) Comparison of simulation models of debris flow. Proceedings of hydraulic engineering, Japan Society of Civil Engineers, 44: 687- 692. (in J apanese with English summary)

Takahama J, Fujita Y, Hachiya K, Sakamoto M (2002) Study on debris flow behavior in a region around a point of abrupt slope reducing. Proceedings of hydraulic engineering, J SCE, 46: 683-688. (in J apanese with English summary)

Takahashi T (1977) A mechanism of occurrence of mud-debris flows and their characteristics in motion. Annals of the Disaster Prevention Research Institute, Kyoto University, 20 (B-2): 405-435. (in J apanese with English summary)

Takahashi T (1980) Debris flow on prismatic open channel. Journal of the Hydraulics Division, ASCE, 106(3): 381- 396.

Takahashi T (2007) Debris Flow: Mechanics, Prediction and Countermeasures. Taylor and Francis, Balkema, 448 pp.

Takahashi T, Kuang SF (1986) Formation of debris flow on varied slope bed. Annals of the Disaster Prevention Research Institute, Kyoto University, 29 (B-2): 345-359. (in 


\section{J apanese with English summary)}

Takahashi T, Nakagawa H (1991) Prediction of Stony Debris Flow Induced by Severe Rainfall. J ournal of the J apan Society of Erosion Control Engineering 44 (3): 12- 19. (in J apanese with English summary)

Takahashi T, Nakagawa H, Satoh H (1988) Sediment hazard risk on a debris flow fan area. Annals of the Disaster Prevention Research Institute, Kyoto University, 31 (B-2): 655- 676. (in J apanese with English summary)

Takahashi T, Inoue M, Nakagawa H, Satofuka Y (2000) Prediction of sediment runoff from a mountain watershed. Proceedings of hydraulic engineering, Japan Society of Civil Engineers, 44: 717- 722. (in J apanese with English summary)

Tsai Y (2007) A debris-flow simulation model for the evaluation of protection structures. J ournal of Mountain Science 4 (3): 193- 202. doi: 10.1007/ s11629-007-0193-2

Tsubaki T, Hashimoto H, Suetsugi T (1982) Grain stresses and flow property of debris flow. Proceedings of the Japan Society of Civil Engineers 317: 79-91. (in Japanese with English summary)

Tsunetaka H, Hotta N, Suzuki T, Ishikawa S (2015) Influence of topographic condition on numerical simulation of debris flow. J ournal of the Japan Society of Erosion Control Engineering 68 (1): 3-12. (in J apanese with English summary)

Wu YH, Liu KF, Chen YC (2012) Comparison between FLO-2D and Debris-2D on the application of application of assessment of granular debris flow hazard with case study. J ournal of Mountain Science 10 (2): 293-304. doi: 10.1007/ s11629-013-2511-1

Zhou GGD, Cui P, Tang J B, Chen HY, Zou Q, Sun QC (2015) Experimental study on the triggering mechanisms and kinematic properties of large debris flows in Wenjia Gully. Engineering Geology 194: 52-61. doi:10.1016/j.enggeo.2014.10.021 


\section{Table:}

Table 1 Physical parameters of the debris-flow material.

\begin{tabular}{lc}
\hline $\begin{array}{l}\text { Density of water: } \rho\left(\mathrm{g} / \mathrm{cm}^{3}\right) \\
\text { Density of sediment particles: } \sigma\left(\mathrm{g} / \mathrm{cm}^{3}\right)\end{array}$ & 1.00 \\
Internal friction angle of the sediment & 2.65 \\
$\quad$ particles: $\phi_{s}$ (deg) & 38.5 \\
Coefficient of the restitution of the sediment & \\
$\quad$ particles: $e$ & 0.85 \\
$\begin{array}{l}\text { Diameter of the sediment particles: } d(\mathrm{~m}) \\
\text { Sediment concentration in the channel }\end{array}$ & 0.20 \\
$\quad$ deposition: $c^{*}$ & 0.60 \\
\hline
\end{tabular}

\section{Figures:}

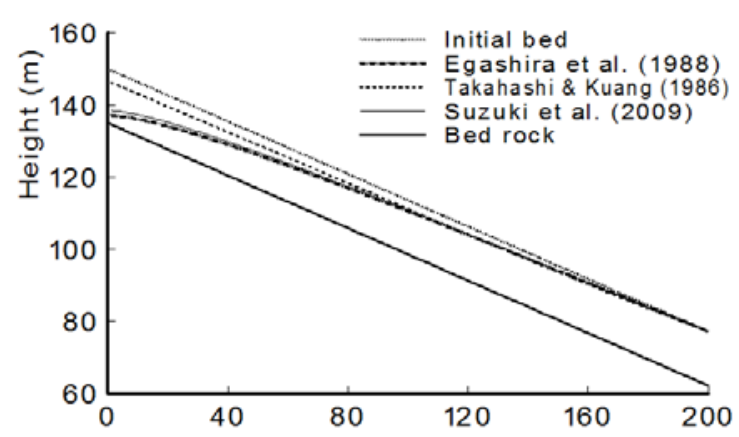

(a) 20-degree bed slope

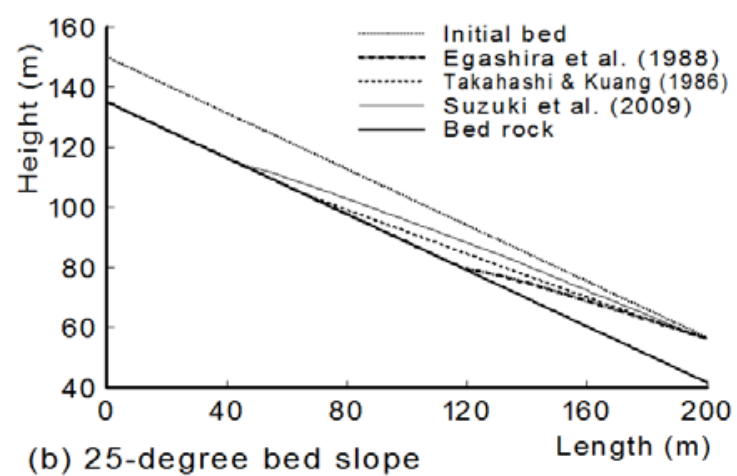

Figure 1 Bed evolution simulated in a flat-bed channel of (a) $20^{\circ}$ and (b) $25^{\circ}$. 


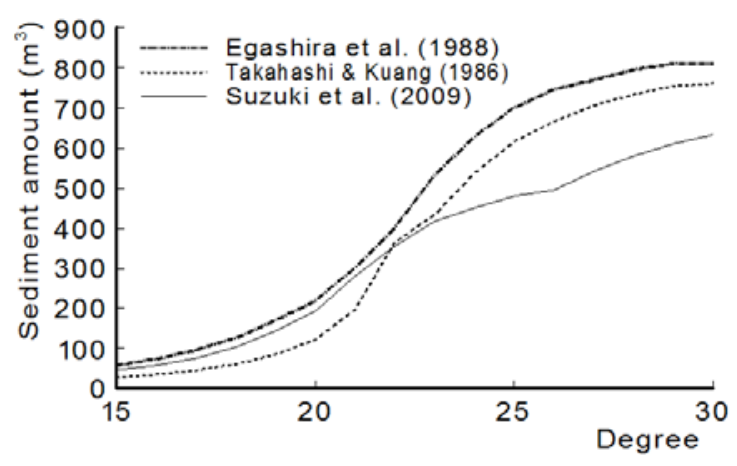

Figure 2 Relationship between channel bed angle and total amount of erosion after $600 \mathrm{~s}$.
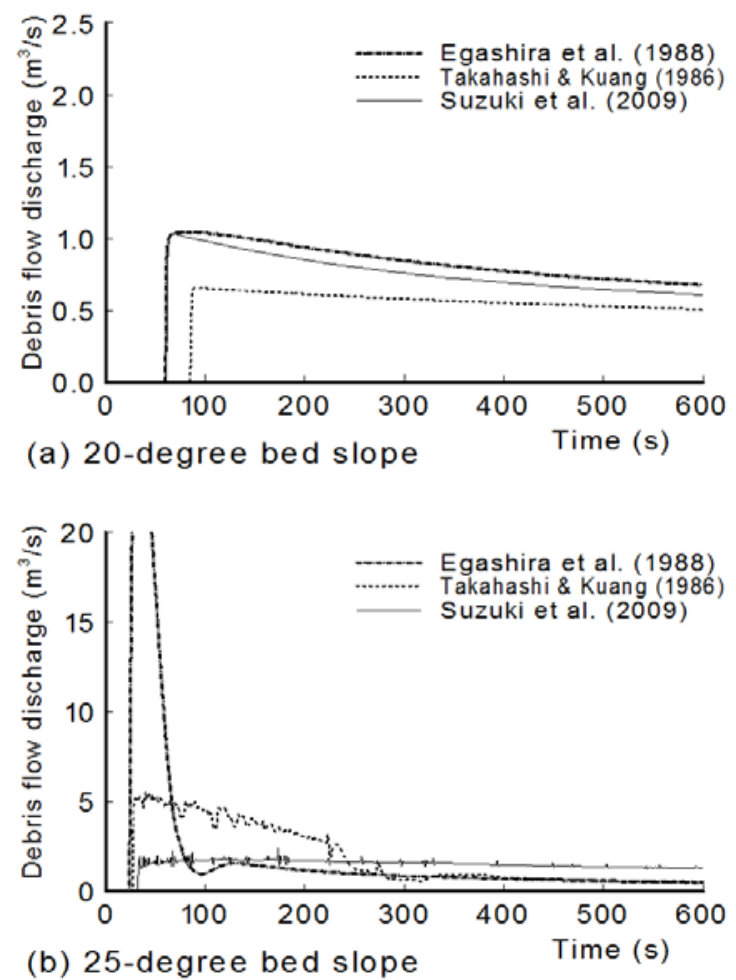

Figure 3 Hydrograph at the lower end in a flat-bed channel of (a) $20^{\circ}$ and (b) $25^{\circ}$. 


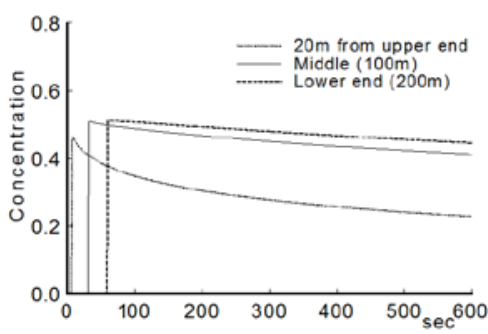

(a) 20 degree, Egashira et al. (1988)

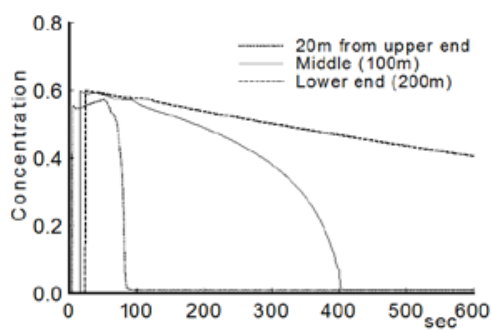

(d) 25 degree, Egashira et al. (1988)
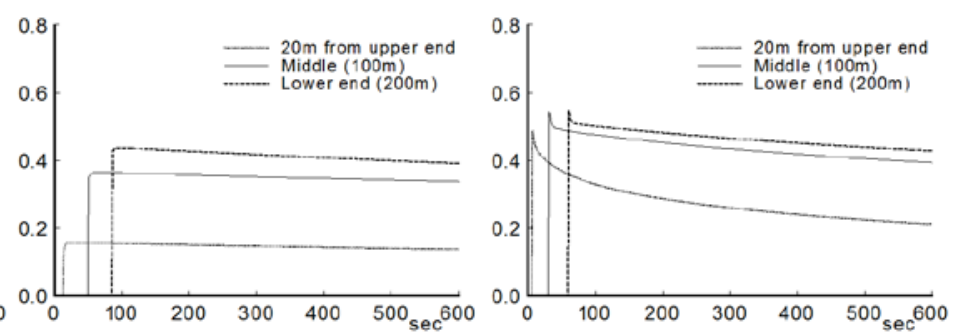

(b) 20 degree, Takahashi \& Kuang (1986) (c) 20 degree, Suzuki et al. (2009)
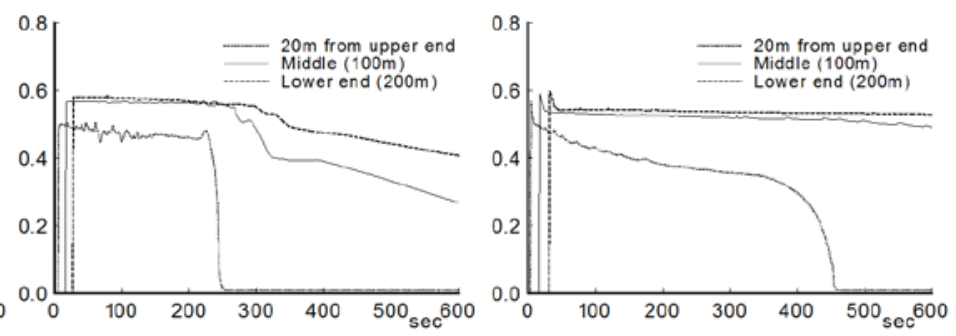

(e) 25 degree, Takahashi \& Kuang (1986) (f) 25 degree, Suzuki et al. (2009)

Figure 4 Time series of sediment concentration at the upper end (20m downstream), middle, and lower end of a flat-bed channel of $20^{\circ}(\mathrm{a}-\mathrm{c})$ and $25^{\circ}(\mathrm{d}-\mathrm{f})$ according to the different entrainment rate equations.
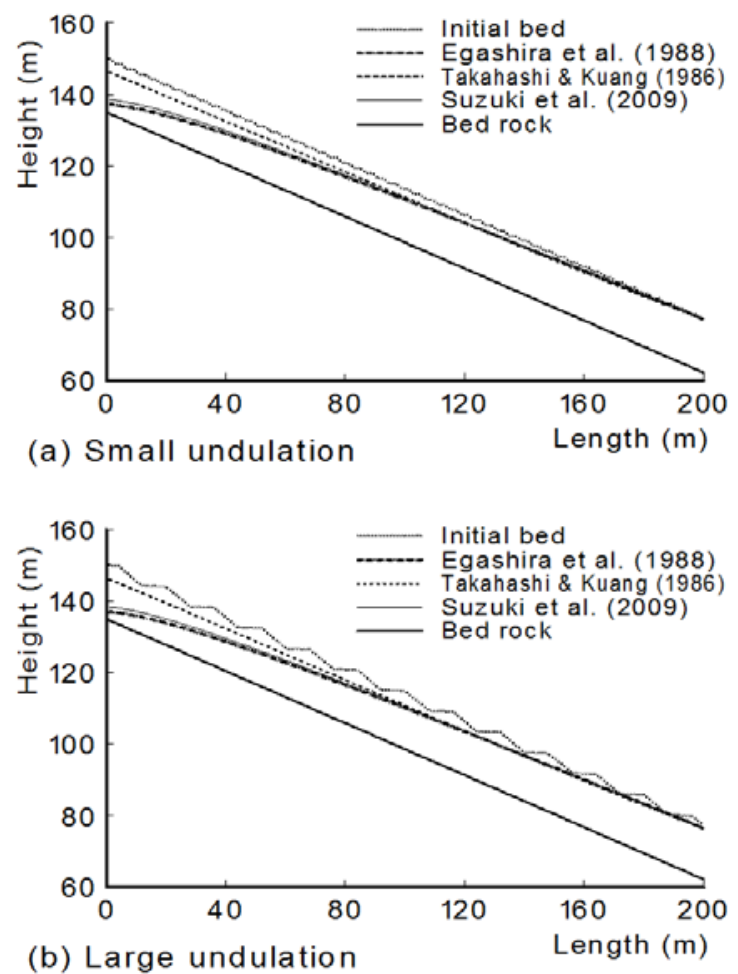

Figure 5 Bed evolution simulated in a $20^{\circ}$ channel with (a) small and (b) large undulations of the bed surface. 


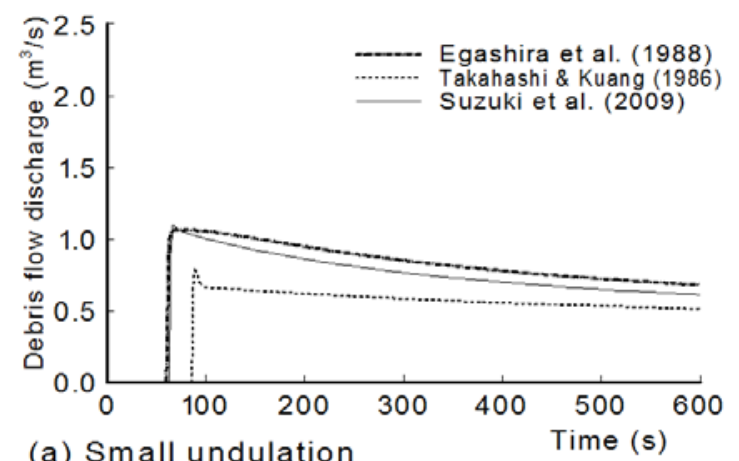
(a) Small undulation

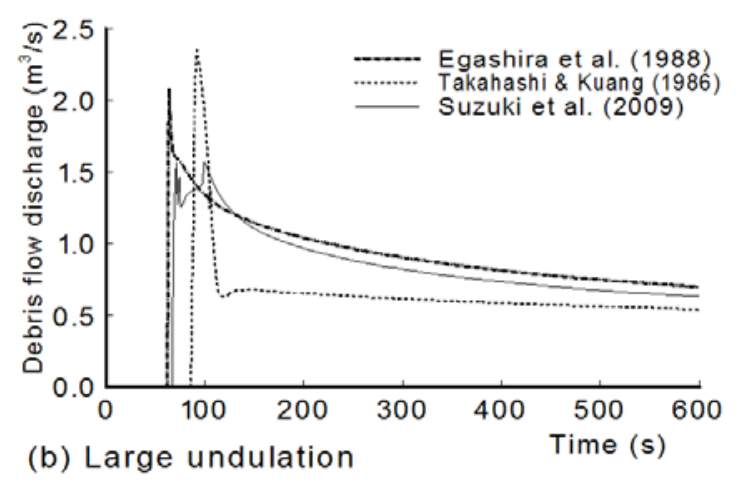

Figure 6 Hydrograph at the lower end in a channel of $20^{\circ}$ with (a) small and (b) large undulations of the bed surface.
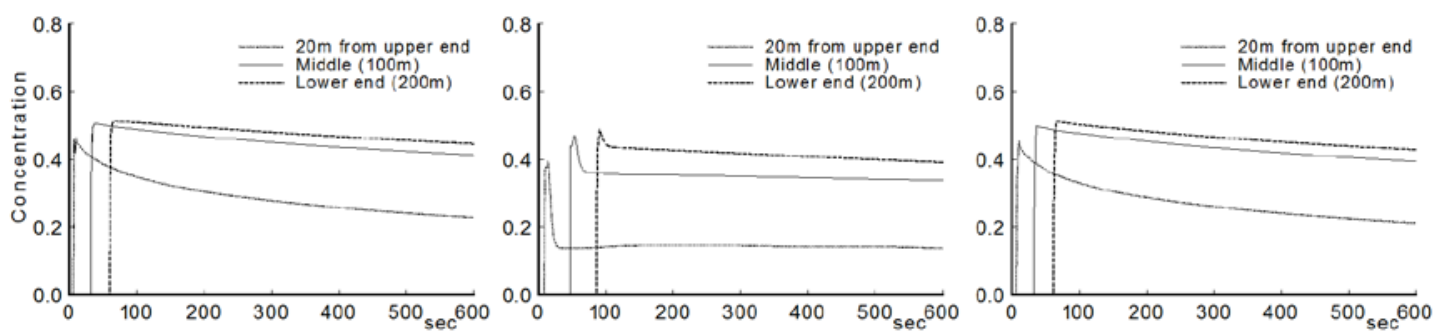

(a) Egashira et al. (1988) with small undulation (b) Takahashi \& Kuang (1986) with small undulation (c) Suzuki et al. (2009) with small undulation
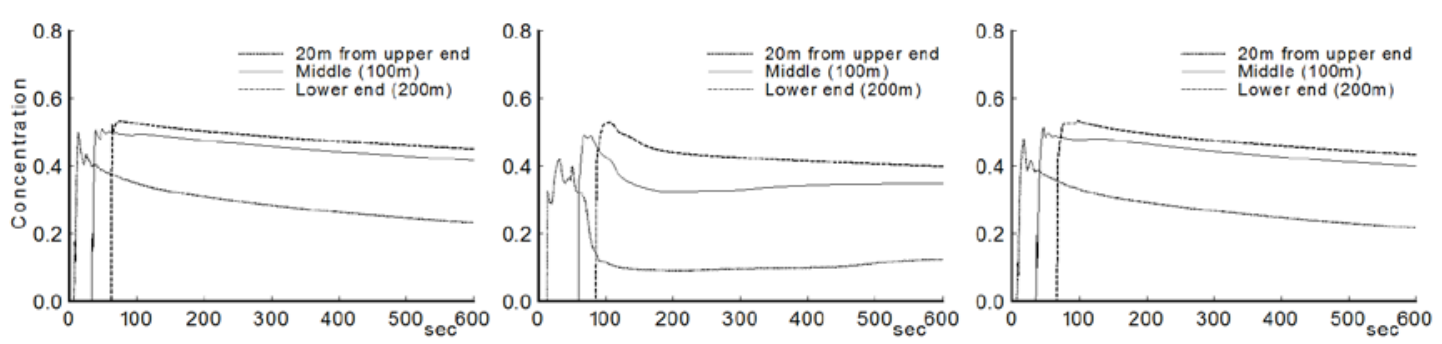

(d) Egashira et al. (1988) with large undulation (e) Takahashi \& Kuang (1986) with large undulation (f) Suzuki et al. (2009) with large undulation

Figure 7 Time series of sediment concentration at the upper end (20m downstream), middle, and lower end of a $20^{\circ}$ channel with small (a-c) and large (d-f) undulations by the different entrainment-rate equations. 